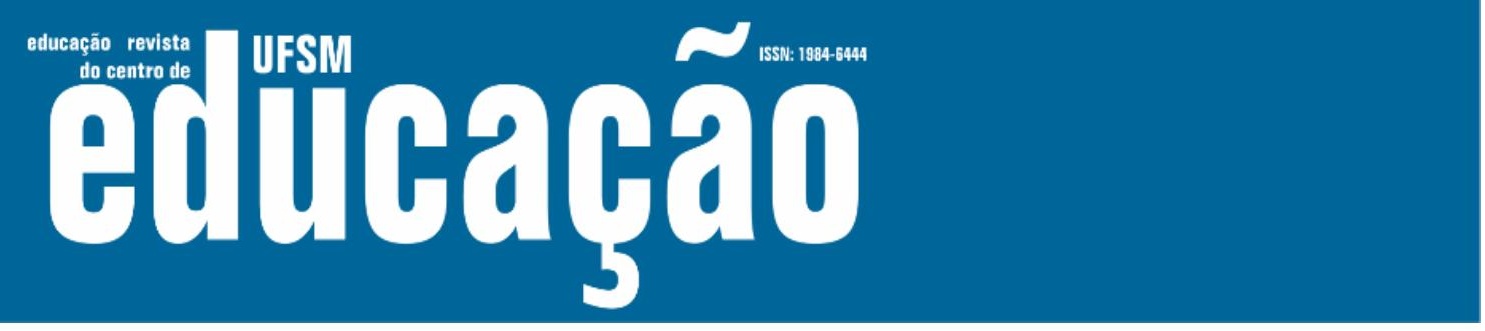

ISSN: 1984-6444 | http://dx.doi.org/10.5902/1984644436332

\title{
Políticas públicas municipais para a educação primária em Pelotas, RS, Brasil (1940-1961)
}

Municipal public policies for primary education in Pelotas, RS, Brazil $(1940-1961)$

Magda de Abreu Vicente

Professora doutora da Fundação Universidade Federal de Rio Grande. Rio Grande, Rio Grande do Sul, Brasil.

magdabreu@gmail.com - http://orcid.org/0000-0003-2583-3263

Giana Lange do Amaral

Professora Associada da Universidade Federal de Pelotas. Pelotas, Rio Grande do Sul, Brasil. gianalangedoamaral@gmail.com - http://orcid.org/0000-0002-1088-9283

Recebido em 10 de janeiro de 2019

Aprovado em 28 de novembro de 2019

Publicado em 24 de junho de 2020

\section{RESUMO}

O presente artigo examina as políticas municipais para a educação na cidade de Pelotas - RS, de 1940 a 1961, com o objetivo de destacar o envolvimento da municipalidade em relação à abertura de escolas e a normatização do ensino primário. $\mathrm{Na}$ análise, de cunho histórico documental, foram consultadas leis, atos, decretos, regimentos e relatórios anuais do município. A investigação demonstrou que, a partir de 1945, houve um considerável aumento de recursos destinados à educação pública municipal. Foram alocadas verbas, principalmente, para a contratação de professores e abertura de escolas primárias isoladas localizadas na zona rural. Tal fato foi incentivado pelo fim da ditadura do governo de Getúlio Vargas, pela criação, em 1942, do Fundo Nacional para o Ensino Primário e pelos encargos que foram atribuídos ao município, a partir da Constituição Federal de 1946, em relação ao financiamento educacional bem como pela influência política do Partido Social Democrata em nível federal, regional e local.

Palavras-chave: Municipalismo; Políticas municipais; Escolas primárias rurais.

\section{ABSTRACT}

The present article evaluates the municipal policies for education in the city of Pelotas - RS, from 1940 to 1961, aiming at emphasizing the city involvement in relation both to the opening of schools and the primary education ruling. In the analysis, which is historical and documental, laws, acts, decreets, school regulations and annual reports were consulted. The investigation demonstrated that, from 1945 on, there was a significant increase in the resources for municipal public education. Funds were 


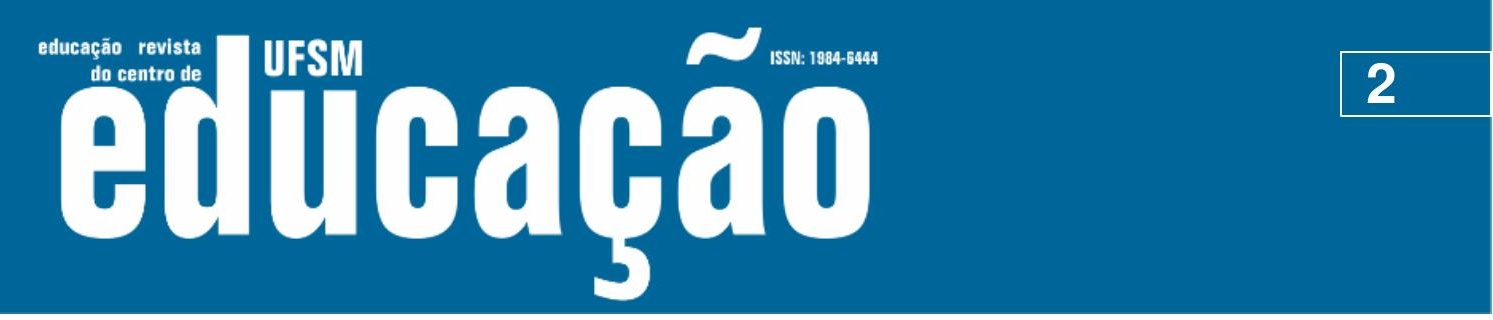

ISSN: 1984-6444 | http://dx.doi.org/10.5902/1984644436332

allocated, mainly for hiring teachers and opening isolated primary schools in the countryside. Such fact was motivated by the end of Getulio Vargas's dictatorial government, by the creation, in 1942, of the National Fund for Primary Education and by the charges attributed to the city, from the 1946 Federal Constitution in relation to the educational financing, as well as by the political influence of the Democrat Social Party in federal, regional, and local level.

Keywords: Municipalism; Municipal policies; Countryside primary schools.

\section{Introdução}

Entre os anos de 1940 a 1961, período de nossa investigação, a política realizada nos municípios brasileiros transitou entre intervenções ditatoriais e eleições democráticas. No Estado Novo (1937-1945), período ditatorial do governo de Getúlio Vargas, a atuação política ficou muito circunscrita a ações de interventores e de militares na esfera estadual e municipal. A supressão e centralização de direitos políticos vinham ao encontro dos movimentos de contestação da liberal democracia na Europa. Este foi um período em que o Congresso Nacional, as Assembleias Legislativas Estaduais e as Câmaras Municipais foram fechadas. Identificado com o fascismo, o Estado Novo propunha a modernização da nação, tendo por base um Estado interventor forte e centralizador, agente fundamental da produção e do desenvolvimento econômico. As eleições democráticas, que ocorreram em 1945, marcaram o final desse regime e o início de um período em que o Brasil viveu um processo de democracia, intenso populismo, urbanização e industrialização em determinadas áreas do país.

Mesmo após a abertura democrática, os governos municipais estiveram fortemente atrelados às determinações políticas em nível estadual e federal. Nesse sentido, no âmbito educacional, manteve-se uma preocupação que remetia aos primórdios da República brasileira e a qual envolvia todas as instâncias governamentais, qual seja a escolarização primária. Figurando como fundamental à tão propalada ordem, progresso, civismo e disciplina do povo mais pobre do país, a educação primária foi sendo alvo de modificações nas constituições de 1934, 1937 e 1946. Nesse quadro, ela foi progressivamente ficando sob responsabilidade dos municípios, como será visto a seguir. 


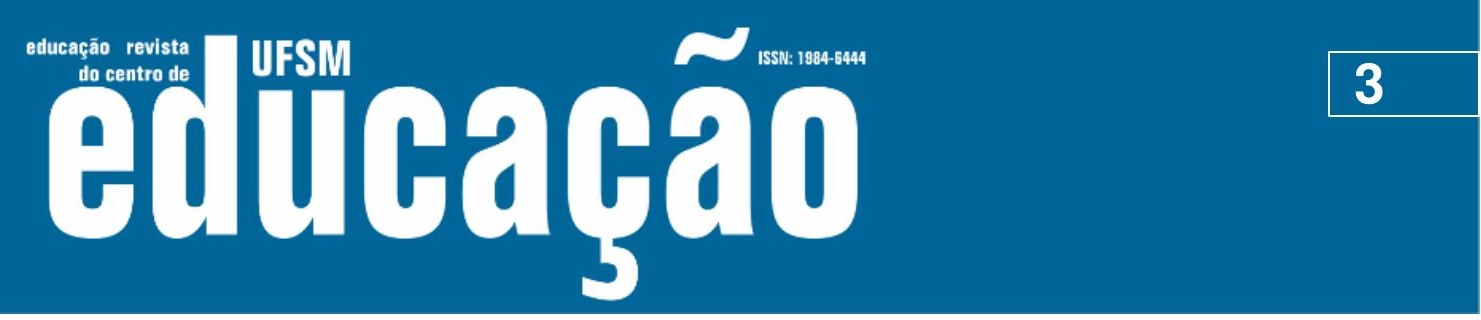

ISSN: 1984-6444 | http://dx.doi.org/10.5902/1984644436332

É importante destacar que a consolidação da emergente República estava atrelada à ideia de que a integração social ocorreria através de um projeto político de nação no qual a escola primária "destinada à maioria da população, deveria difundir os saberes elementares e os rudimentos das ciências físicas, naturais e sociais, enquanto a escola secundária atenderia às elites" (SOUZA, 2008, p. 19). Assim, apenas o ensino das quatro primeiras séries seria suficiente para a maioria da população brasileira. Para Hilsdorf (2005), a crescente urbanização e, ao mesmo tempo, o êxodo rural foram outros fatores importantes para discutir a escolarização da população'.

No que diz respeito ao estado do RS, principalmente durante o período da nacionalização do ensino (1937-1945), o governo estadual investiu no reaparelhamento e racionalização da instrução pública, o que levou também a um significativo aumento da rede escolar primária em âmbito estadual e municipal, consubstanciando com o fechamento das escolas particulares e estabelecendo o "reconhecimento e a supervisão direta do sistema educativo pelo Estado" (TAMBARA; QUADROS; BASTOS, 2007, p. 323). Nesse estado, houve uma significativa expansão da escolarização primária, principalmente devido à instalação do Centro de Pesquisas e Orientações Educacionais (CPOE) - que funcionou de 1943 a 1971 - e do governo de Leonel Brizola (1959 e 1963). O governo brizolista ficou conhecido pelo projeto Nenhuma Criança Sem Escola no Rio Grande do Sul que expandiu a construção de prédios escolares, conhecidos como Brizoletas (escolas pequenas construídas em madeira, matéria prima abundante, principalmente no meio rural).

Em Pelotas, o primeiro prefeito eleito com voto popular foi Joaquim Duval em 1947. Os estudos sobre a educação pública nesse município, relativos ao período posterior a 1930, ainda são escassos. Assim, com o intuito de contribuir com reflexões sobre a História da Educação nacional, regional e local, buscamos investigar documentos e analisar o que Saviani (2006, p.31) denominou como segundo período do "longo século XX" da história da escola pública brasileira, ou seja, de 1931 a 1961. Para o autor, esse foi um período de regulamentação nacional do ensino e do ideário pedagógico renovador, por se tratar de um momento em que surgiram diretrizes nacionais e preceitos escolanovistas que influenciaram as políticas educativas ${ }^{2}$. No 


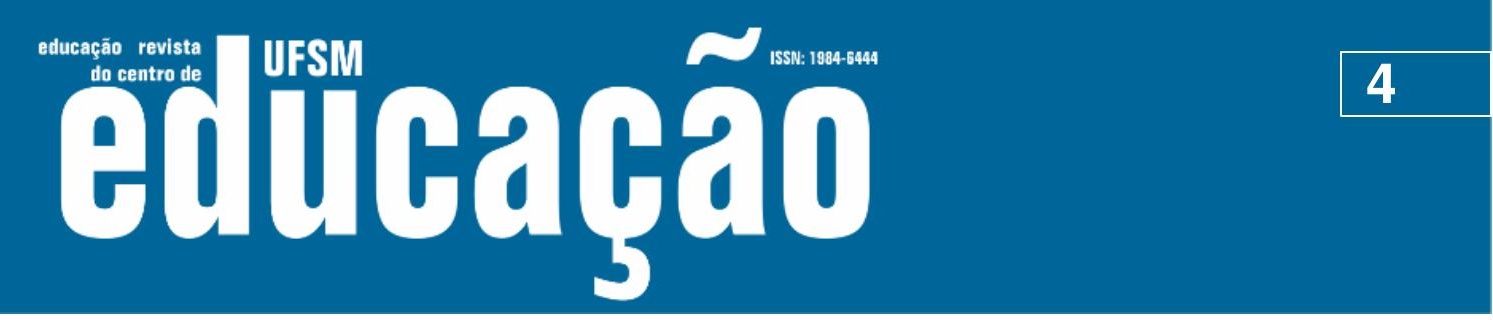

ISSN: 1984-6444 | http://dx.doi.org/10.5902/1984644436332

entanto, ao buscar as legislações do município de Pelotas desse período, não conseguimos elementos suficientes para investigar os anos de 1931 até 1940. Desse modo, nossa investigação ficou restrita ao período de 1940 até 1961.

Assim, o presente artigo examina as legislações municipais relativas à educação pelotense entre os anos de 1940 a 1961 a fim de investigar informações referentes ao ensino primário e realizar um levantamento das escolas primárias municipais criadas e das legislações que as regiam de modo que pudéssemos entender suas conduções normativas. Portanto, analisamos uma gama de leis, atos, decretos e regimentos municipais, recorrendo também ao Relatório Municipal de Pelotas referente ao ano de 1947. Como resultado desse estudo, as legislações encontradas indicaram que houve um considerável aumento de recursos destinados à educação a partir de 1945. O que se viu foi uma significativa elevação da contratação de professores, aumento de abertura de escolas e, consequentemente, de estudantes, principalmente durante o mandato do prefeito Joaquim Duval (19481951), que criou quase 30 escolas primárias, em sua maioria, rurais, fato que não foi identificado em outros mandatos. Suas possíveis causas serão aqui levantadas.

Nossa operação historiográfica, de cunho documental, teve como principais suportes teóricos os trabalhos de Tambara; Quadros; Bastos (2007); Vilela; Ribeiro (2011); Loner (1999) e Souza (2008).

É interessante mencionar que essa investigação, por fazer amplo levantamento das escolas criadas durante o período, passa a ser uma possível fonte de consulta para outros pesquisadores da área e abre a possibilidade para a realização de uma análise mais ampla em relação aos fatores políticos que envolveram o cenário local e suas implicações em nível federal e estadual, bem como possíveis investigações sobre a cultura escolar desses espaços educativos.

\section{O processo de inserção municipal na educação primária}

O envolvimento das instâncias governamentais em relação à educação acompanhou as exigências legais e suas transformações, principalmente a partir das constituições de 1934, 1937 e 1946. Na constituição de 1934, os municípios passaram 


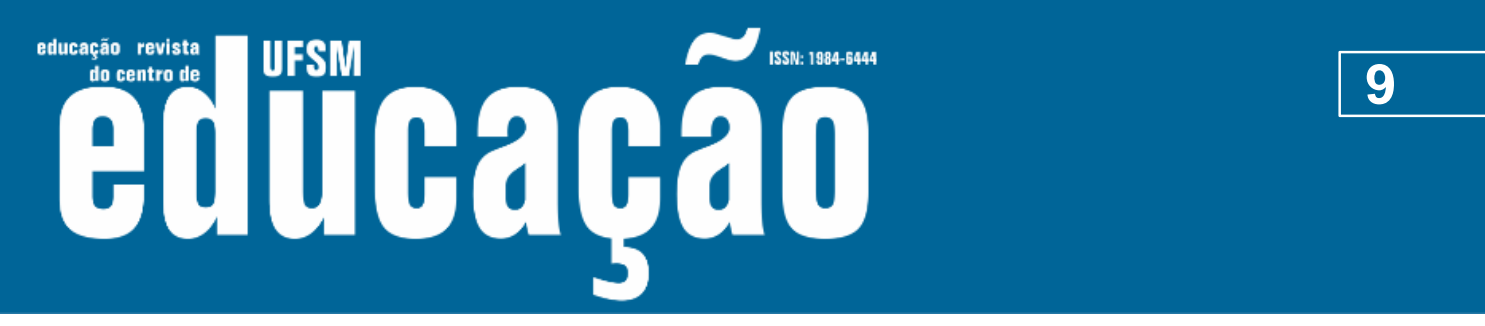

ISSN: 1984-6444 | http://dx.doi.org/10.5902/1984644436332

\section{Continuação Tabela 1:}

\begin{tabular}{|c|c|c|c|}
\hline $\begin{array}{l}\text { N. e data } \\
\text { do decreto }\end{array}$ & Prefeito & $\begin{array}{l}\text { Escolas municipais criadas ou nomeadas } \\
\text { pelo referido decreto }\end{array}$ & $\begin{array}{l}\text { Estágio da } \\
\text { escola criada }\end{array}$ \\
\hline $\begin{array}{l}\text { n. } 123 \\
18 / 04 / 1947\end{array}$ & Procópio Duval & $\begin{array}{l}\text { Cascata, subdistrito de Santa Eulália, distrito } \\
\text { de Capão do Leão: Professor Francisco } \\
\text { Araújo }\end{array}$ & $1^{o}$ \\
\hline $\begin{array}{l}\text { n. } 136 \\
07 / 10 / 1948\end{array}$ & Joaquim Duval & $\begin{array}{l}\text { Distrito Capão do Leão/Granja Pavão: nome } \\
\text { não informado e não localizado }\end{array}$ & $1^{o}$ \\
\hline $\begin{array}{l}\text { n. } 149 \\
21 / 03 / 1949\end{array}$ & Joaquim Duval & $\begin{array}{l}\text { Distrito de Dunas, subdistrito do Quilombo: } \\
\text { nome não informado e não localizado }\end{array}$ & $1^{o}$ \\
\hline $\begin{array}{l}\text { n. } 150 \\
21 / 03 / 1949\end{array}$ & Joaquim Duval & $\begin{array}{l}\text { Distrito do Capão do Leão/Passo das Pedras } \\
\text { de Cima: Na residência do Sr. João Khun: } \\
\text { José Saturnino (Decreto n. 169/1949, nomeia } \\
\text { a escola) }\end{array}$ & $1^{\circ}$ \\
\hline $\begin{array}{l}\text { n.151 } \\
21 / 03 / 1949\end{array}$ & Joaquim Duval & $\begin{array}{l}\text { Distrito do Capão do Leão/Colônia Santa } \\
\text { Rita: Próximo a residência do Sr. João } \\
\text { Zafalon: Dr. Carlos Barbosa (Decreto n. } \\
\text { 169/1949, nomeia a escola) }\end{array}$ & $1^{\circ}$ \\
\hline $\begin{array}{l}\text { n. } 152 \\
26 / 03 / 1949\end{array}$ & Joaquim Duval & $\begin{array}{l}\text { Subdistrito Cerrito Alegre/Posto Branco: } \\
\text { nome não informado e não localizado }\end{array}$ & $1^{\circ}$ \\
\hline $\begin{array}{l}\text { n. } 172 \\
17 / 08 / 1949\end{array}$ & Joaquim Duval & $\begin{array}{l}\text { Distrito de Dunas, subdistrito Cerrito Alegre } \\
\text { (na colônia Osório): Euclydes da Cunha } \\
\text { (Decreto n. 184, de 30/12/1949, nomeia a } \\
\text { escola) }\end{array}$ & $1^{0}$ \\
\hline $\begin{array}{l}\text { n. } 186 \\
14 / 01 / 1950\end{array}$ & Joaquim Duval & $\begin{array}{l}\text { Distrito de Dunas Subdistrito De Santa } \\
\text { Silvana - na Colônia São José: Para } \\
\text { funcionar no prédio adquirido pela Lei n. } 112 \text {, } \\
\text { de 25/7/49: Escola Caldas Junior (Decreto n. } \\
\text { 188/1950, nomeia a escola) }\end{array}$ & $1^{\circ}$ \\
\hline $\begin{array}{l}\text { n. } 187 \\
14 / 01 / 1950\end{array}$ & Joaquim Duval & $\begin{array}{l}\text { Vila da Graça (prédio da Cia. Nacional de } \\
\text { óleos Linhaça): Afonso Vizeu (Decreto n. } \\
\text { 193/1950, nomeia a escola) }\end{array}$ & $2^{o}$ \\
\hline $\begin{array}{l}\text { n. } 199 \\
31 / 03 / 1950\end{array}$ & Joaquim Duval & $\begin{array}{l}\text { Distrito de Dunas estrada da Gama: nas } \\
\text { proximidades da casa de Carlos Ludke: } \\
\text { Alfredo Clemente Pinto (Decreto n. } 213 / 1950 \text {, } \\
\text { nomeia a escola) }\end{array}$ & $1^{0}$ \\
\hline $\begin{array}{l}\text { n. } 208 \\
28 / 07 / 1950\end{array}$ & Joaquim Duval & $\begin{array}{l}\text { Distrito do Capão Do Leão lugar denominado } \\
\text { "Reserva" (1 }{ }^{\mathrm{a}} \text { zona): Conde de Afonso Celso } \\
\text { (Decreto n. } 213 / 1950 \text {, nomeia a escola) }\end{array}$ & $1^{0}$ \\
\hline
\end{tabular}




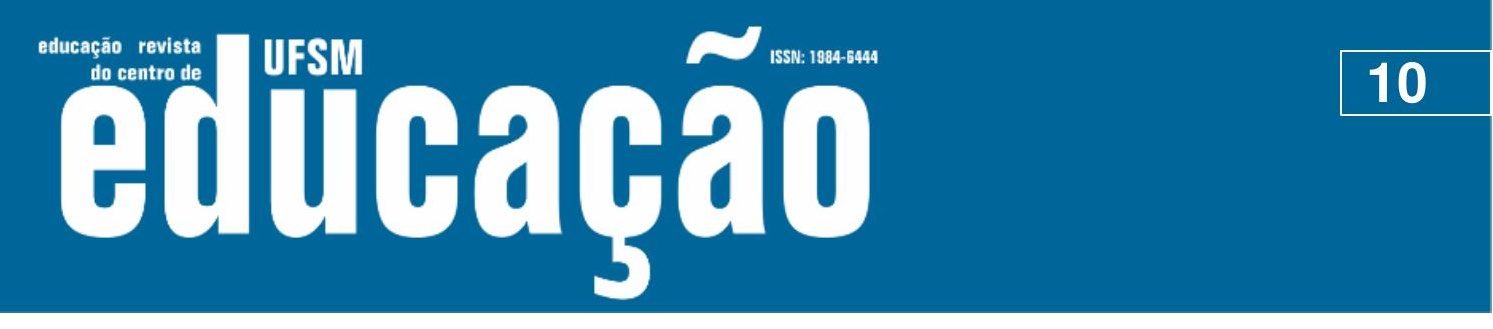

ISSN: 1984-6444 | http://dx.doi.org/10.5902/1984644436332

\section{Continuação Tabela 1:}

\begin{tabular}{|c|c|c|c|}
\hline $\begin{array}{l}\text { N. e data } \\
\text { do decreto }\end{array}$ & Prefeito & $\begin{array}{l}\text { Escolas municipais criadas ou nomeadas } \\
\text { pelo referido decreto }\end{array}$ & $\begin{array}{l}\text { Estágio da } \\
\text { escola criada }\end{array}$ \\
\hline $\begin{array}{l}\text { n. } 209 \\
31 / 07 / 1950\end{array}$ & Joaquim Duval & $\begin{array}{l}\text { Edifício do "Asilo São Benedito": Luciana de } \\
\text { Araújo (Decreto n. 213/1950, nomeia a } \\
\text { escola) }\end{array}$ & $2^{0}$ \\
\hline $\begin{array}{l}\text { n. } 217 \\
22 / 08 / 1950\end{array}$ & Joaquim Duval & $\begin{array}{l}\text { Distrito de Dunas subdistrito de Santa } \\
\text { Silvana Colônia São Domingos: Professor } \\
\text { José Seixas (Decreto n. 223/1950, nomeia a } \\
\text { escola) }\end{array}$ & $1^{\circ}$ \\
\hline $\begin{array}{l}\text { n. } 221 \\
24 / 10 / 1950\end{array}$ & Joaquim Duval & $\begin{array}{l}\text { Distrito do Capão do Leão. No SubDistrito de } \\
\text { Quilombo" Rincão da Cruz (granja } \\
\text { Donatília): Visconde de Souza Soares } \\
\text { (Decreto n. 236/1951, nomeia a escola) }\end{array}$ & $1^{\circ}$ \\
\hline $\begin{array}{l}\text { n. } 226 \\
13 / 01 / 1951\end{array}$ & Joaquim Duval & $\begin{array}{l}\text { Distrito do Capão do Leão, subdistrito de } \\
\text { Santa Eulália: Escola Benjamim Manoel } \\
\text { Amarante }\end{array}$ & $1^{\circ}$ \\
\hline $\begin{array}{l}\text { n. } 287 \\
14 / 08 / 1954\end{array}$ & Mário Meneghetti & $\begin{array}{l}\text { Distrito do Capão do Leão subdistrito de } \\
\text { Santa Eulália-Colônia Umbú: Escola Cel. } \\
\text { Guilherme Echenique }\end{array}$ & $1^{0}$ \\
\hline $\begin{array}{l}\text { n. } 303 \\
04 / 10 / 1955\end{array}$ & Mário Meneghetti & $\begin{array}{l}\text { Distrito do Capão do Leão - Na Palma } \\
\text { (Fazenda Federal): Escola Manoel Serafim } \\
\text { Gomes de Freitas }\end{array}$ & $1^{0}$ \\
\hline $\begin{array}{l}\text { n. } 304 \\
04 / 10 / 1955\end{array}$ & Mário Meneghetti & $\begin{array}{l}\text { Distrito do Capão do Leão - Horto Florestal - } \\
\text { Fazenda Federal: Dr. Ildefonso Simões } \\
\text { Lopes }\end{array}$ & $1^{0}$ \\
\hline $\begin{array}{l}\text { n. } 305 \\
04 / 10 / 1955\end{array}$ & Mário Meneghetti & $\begin{array}{l}\text { Distrito do Capão do Leão - No Campestre: } \\
\text { Alcides Maia }\end{array}$ & $1^{0}$ \\
\hline $\begin{array}{l}\text { n. } 306 \\
04 / 10 / 1955\end{array}$ & Mário Meneghetti & $\begin{array}{l}\text { Distrito de Dunas. Subdistrito de Cerrito } \\
\text { Alegre - no Passo da Capivara: Monteiro } \\
\text { Lobato }\end{array}$ & $1^{0}$ \\
\hline $\begin{array}{l}\text { n. } 391 \\
10 / 10 / 1959\end{array}$ & Adolfo Fetter & $\begin{array}{l}\text { Grupo Escolar na Vila Hilda (nome não } \\
\text { informado e não localizado) }\end{array}$ & $\begin{array}{l}\text { Não } \\
\text { informado }\end{array}$ \\
\hline
\end{tabular}

Fonte: Leis, Atos e Decretos municipais. Disponíveis no Almoxarifado Municipal de Pelotas e no site: www.pelotas.com.br

O item "estágio da escola", presente na tabela n. 1, demonstra o local em que as escolas foram criadas, identificando que a maioria era em zona rural, por serem de primeiro estágio, conforme observado a partir do Decreto de n. 116 (PREFEITURA..., 


\section{تilloapão}

ISSN: 1984-6444 | http://dx.doi.org/10.5902/1984644436332

primárias, nesse período, estavam a cargo do governo estadual e de instituições privadas.

Um dado que se destacou a partir da análise da tabela n. 1 foi a criação de 27 escolas municipais, no período de 1948 a 1951, durante o governo do prefeito Joaquim Duval. Um número considerado relevante em relação ao apontado em anos anteriores e posteriores, no que tange à realidade municipal. Nesse sentido, cotejamos tais dados com o Relatório Municipal de 1947 em que podemos observar melhor a progressão escolar desde o início da década de 1940.

Tabela 2: Dados referentes a Educação Municipal em Pelotas-RS (1940-1946)

\begin{tabular}{c|c|c|c|c|}
\hline Anos & $\begin{array}{c}\text { Unidades } \\
\text { Escolares }\end{array}$ & $\begin{array}{c}\text { Matrícula } \\
\text { Geral }\end{array}$ & Professorado & $\begin{array}{c}\text { Despesas com educação } \\
\text { Cr\$ }\end{array}$ \\
\hline 1940 & 52 & 3164 & 118 & $405.000,00$ \\
\hline 1941 & 61 & 3309 & 147 & $534.272,00$ \\
\hline 1942 & 52 & 3003 & 133 & $431.680,00$ \\
\hline 1943 & 58 & 3372 & 152 & $464.880,00$ \\
\hline 1944 & 52 & 3608 & 152 & $529.830,00$ \\
\hline 1945 & 51 & 4210 & 184 & $1.012 .770,00$ \\
\hline 1946 & 58 & 4612 & 190 & $1.386 .504,00$ \\
\hline
\end{tabular}

Fonte: Prefeitura Municipal de Pelotas, 1947c.

Embora os dados presentes na tabela n. 2 não englobem também o governo de Joaquim Duval, podemos considerar um substancial crescimento do envolvimento do município com a educação primária, principalmente a partir de 1945, quando há um relevante aumento dos gastos com educação dado que podemos constatar não só pelo maior número de matrículas e de professores, mas também pela quase duplicação desses gastos, se compararmos os percentuais referentes a 1945 e 1946 apenas com o ano de 1944.

Esses dados nos propiciam algumas possibilidades de análise. A primeira é que o governo de Joaquim Duval não foi o primeiro a intensificar sua preocupação 


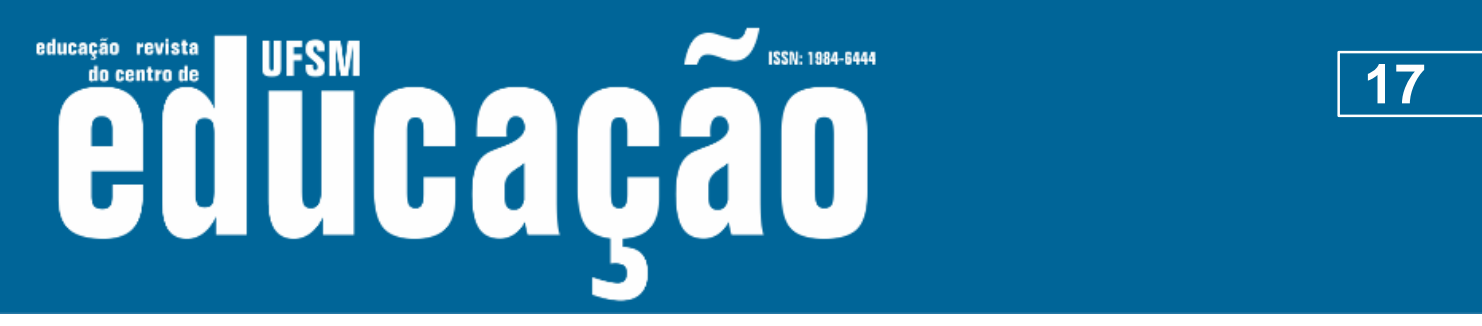

ISSN: 1984-6444 | http://dx.doi.org/10.5902/1984644436332

[...] de 1948 para cá, novos encargos, pois só de professoras são mais de 102, aumento que se explica porque tive oportunidade de criar mais de 30 escolas, além de haver ampliado alguns grupos escolares. Além destas nomeações, foram criados 26 cargos, sendo 10 no corpo de bombeiros e na assistência pública e os 16 restantes se repartem por diversos serviços da Prefeitura (DUVAL, 1951, p.6) [grifo nosso].

Ainda durante o mesmo discurso, o candidato Adolfo Fetter prometia dar sequência às políticas iniciadas no governo de Joaquim Duval, em que cabe ressaltar, o longo, mas interessante trecho, referindo-se ao ensino primário:

No que tange à instrução primária, trabalharemos para expandi-la ao máximo, já criando escolas em qualquer zona do município onde a população em idade escolar o exigir, já continuando a manter a equipe de professores de letras e especializados em número suficiente para atender as crianças que se matricularam nas escolas municipais. Continuaremos cuidando da construção de mais prédios escolares iguais aos modernos e confortáveis, já edificados em várias zonas rurais do município, a fim de que professores e alunos disponham de ambiente confortável com os requisitos recomendados pela moderna pedagogia. [...] Não descuidaremos também a orientação do ensino profissional na escola primária, que já deve cuidar do rumo a ser seguido pelos alunos, dos quais a maioria já tem de ganhar o seu sustento ao deixar os bancos da escola primária. Quanto aos prédios da cidade, todos próprios municipais, providenciaremos a ampliação dos dois únicos que ainda carecem desta medida, dos grupos escolares "Bibiano de Almeida" e "Dr. Balbino Mascarenhas" como na instalação de pavilhões serem aproveitados para festas cívicas e recreativas, tão indispensáveis a boa formação das crianças. Manteremos a linha de auxílio a escolas particulares, cedendo professores as de ensino gratuito, subvencionando outras, para que de uma perfeita colaboração entre associações privadas e o poder público seja ampliada cada vez mais a rede escolar, afim de que ninguém alegue a falta de escolas para a matricula de seus filhos ou tutelados. Não olvidaremos os professores, proporcionando-lhes cursos de aperfeiçoamento, melhorias materiais e vantagens de carreira, enfim, dando-lhes toda assistência que requer a sua elevada missão [...] (CONSTITUIU..., 1951, p.6).

Como podemos notar, o candidato referia-se sempre à sua situação partidária, reforçando as ações de Duval em relação à educação e afirmando sua continuidade. Apesar de o candidato não ter sido eleito em 1951, o foi em 1956. No entanto, suas ações não se coadunaram com o discurso uma vez que a promessa de continuidade na construção de prédios, por exemplo, não foi consolidada conforme se pode comprovar pela tabela 1, que demonstra a criação de apenas um grupo escolar na sua gestão municipal. Durante as outras gestões, tanto posteriores quanto anteriores ao governo de Duval, 17 escolas ao total foram criadas de acordo com os dados que esta pesquisa acessou. 


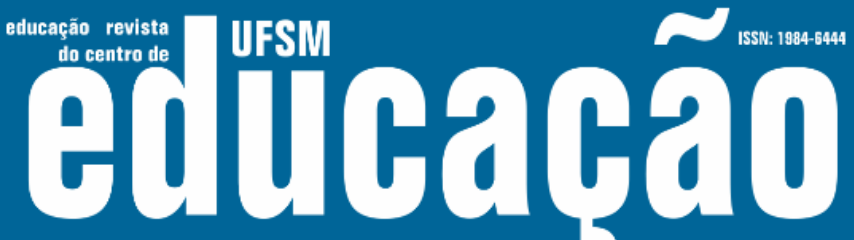

ISSN: 1984-6444 | http://dx.doi.org/10.5902/1984644436332

o número de escolas rurais existentes: em 1948, o governo estadual construiu 248 escolas; já em 1955, esse número foi elevado para 346 escolas rurais (ALMEIDA, 2001, p. 74) o que evidencia também um envolvimento do governo estadual na construção de escolas rurais.

Em Pelotas, como apontaram os dados, a educação primária estava bem dividida entre provimento municipal e estadual. No entanto, podemos afirmar que a década de 1940 e início de 1950 foi um momento em que a municipalidade aumentou sua responsabilidade para com a educação indo desde o investimento em normatização da educação ao aumento de escolas isoladas localizadas predominantemente em zonas rurais. Pelo número de alunos atendidos, porém, ainda era na zona urbana que se concentrava a maior parte das matrículas municipais, o que nos faz acreditar ser ali que se alocava a maior parte dos recursos destinados à educação, fossem eles físicos ou humanos. Isso seria uma contradição, se pensarmos que o estado do Rio Grande do Sul ainda tinha um maior contingente populacional localizado na zona rural, como comprovam os censos do IBGE referentes aos anos de 1940 e $1950^{6}$.

O fato de o Partido Social Democrata ter assumido destaque em nível nacional, municipal e também estadual, certamente facilitou acordos trazendo subvenções e ajuda externa para as políticas locais. Demonstramos que, no caso do município pelotense, os anos de 1945 até 1951 foram momentos de apogeu na criação de escolas primárias e aumento de professores e matrículas ao passo que tanto governantes anteriores, quanto posteriores obtiveram maior esforços apenas em organizar a educação, como exemplificam os decretos-lei n. 78 (PREFEITURA..., 1945), n. 116 (PREFEITURA...,1947b), n. 246 (PREFEITURA...,1951) e n. 326 (PREFEITURA...,1957), que vinham regular o cotidiano escolar. Padronizavam-se horários, ingressos, regulamentava-se a profissão docente e instituíam-se regras para o espaço da escola ou mantinha-se o que já havia sido implantado, sem, no entanto, haver de parte de outros prefeitos uma maior expansão de prédios.

Estranhamos que o prefeito Adolfo Fetter, também do PSD, que assumiu a prefeitura de Pelotas em 1956, não tenha seguido a mesma postura administrativa, qual seja a de expandir o ensino primário, mas apenas manter o já instituído. É 


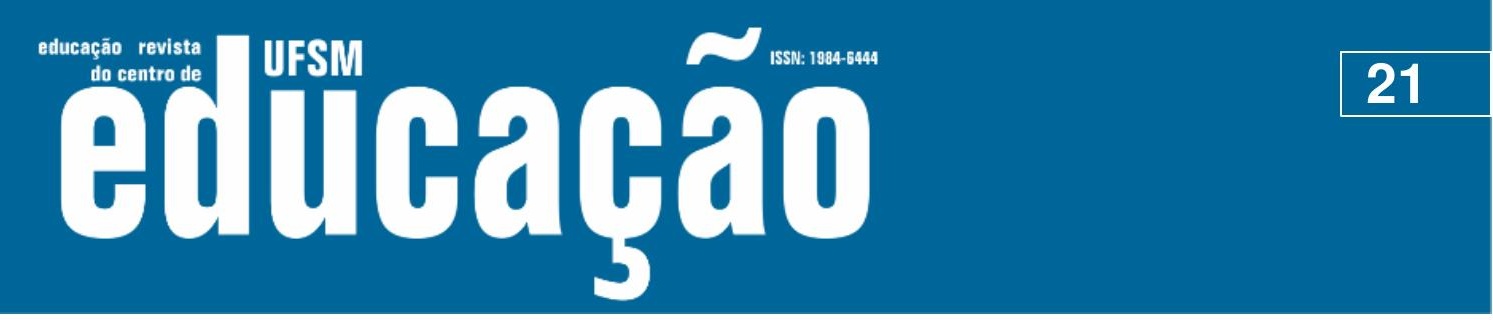

ISSN: 1984-6444 | http://dx.doi.org/10.5902/1984644436332

possível que o fato de o prefeito Joaquim Duval ter assumido imediatamente após o furor da nacionalização o tenha influenciado a abrir tantas escolas em comparação a outros governantes do período analisado, fato que se indica a possibilidade de análise de outros historiadores da educação. Aqui, consideramos relevante recordar as palavras de Ragazzini (2001, p. 24) sobre a necessidade de o historiador entender que nem sempre o esforço de análise das fontes pode ser colocado sobre os ombros de um único pesquisador uma vez que se deve revelar "quando e em que condição é possível produzir resultados acertados e se existem referências suficientes às fontes ou quando tais referências são ainda insuficientes", tal qual consideramos importante investigações complementares a temática sobre o investimento no ensino primário nessas décadas.

Destacamos ainda a necessidade de maiores estudos que aprofundem aspectos da história da educação pelotense no período posterior ao ano de 1930 uma vez que nossas investigações indicam particularidades locais em âmbito municipal. $O$ artigo aponta para a possibilidade de uma investigação que esmiúce a rede de sociabilidades que envolveu os governos municipais de modo a aprimorar os dados levantados. Também seria pertinente nestes estudos vindouros o uso de fontes orais, iconográficas ou de periódicos que apontassem para a cultura escolar existente nas instituições educacionais elencadas.

\section{Referências}

ALMEIDA, Dóris Bittencourt. A educação rural como processo civilizador. In: STEPHANOU, Maria; BASTOS, Maria Helena Camara (Orgs). Histórias e memórias da educação no Brasil. Rio de Janeiro: Editora Vozes, 2005, p. 278-295.

ALMEIDA, Dóris Bittencourt. Vozes esquecidas em horizontes rurais: histórias de professores. Dissertação (Dissertação em Educação). Universidade Federal do Rio Grande do Sul. Programa de Pós-Graduação em Educação. 2001. $263 f$.

A PALAVRA. Discurso do Dr. Joaquim Duval. Pelotas, 13 fev. 1948, p. 1.

BARROZO, Vanessa Teixeira. O ensino primário em Pelotas (1912-1980). Almanaque do Bicentenário de Pelotas, Pelotas, v. 3, p. 451-170, 2014.

BRASIL. Constituição da República dos Estados Unidos do Brasil. 16 de jul. 1934. 


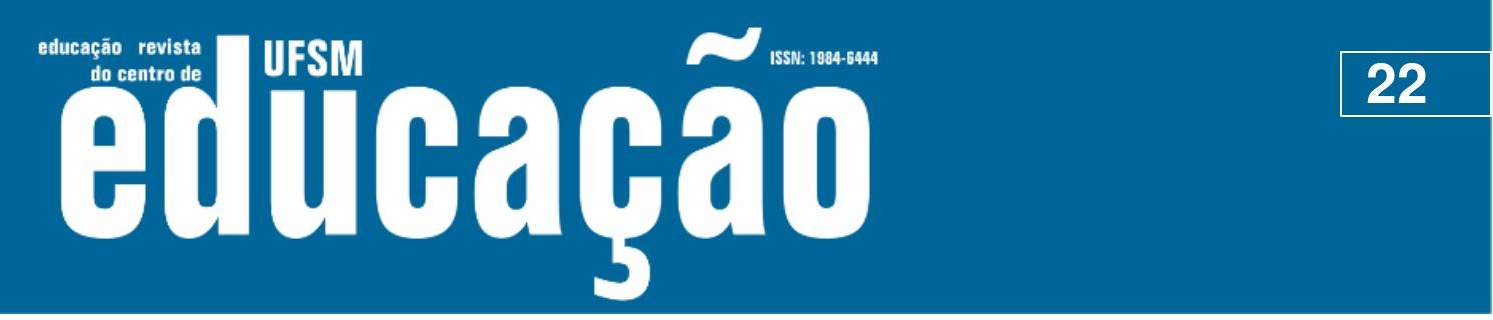

ISSN: 1984-6444 | http://dx.doi.org/10.5902/1984644436332

BRASIL. Constituição da República dos Estados Unidos do Brasil. 10 de nov. 1937.

BRASIL. Constituição da República dos Estados Unidos do Brasil. 18 de set. 1946.

CÂMARA Municipal de Pelotas. Aprovada a Lei do Orçamento para o próximo exercício: 125 milhões de cruzeiros. Diário Popular. Pelotas, 14 dez. 1955, p. 3.

CONSTITUIU verdadeira consagração as candidaturas de Adolfo Fetter e Waldemar Gonçalves da Silva - o gigantesco comício pessedista de sexta-feira. Diário Popular. Pelotas, 21 out. 1951, p. 6.

DUVAL, Joaquim. Discurso pronunciado pelo Dr. Joaquim Duval no Comíssio Pessedista realizado no largo da prefeitura. Diário Popular. Pelotas, 1 nov. 1951, p. 6.

HILSDORF, Maria Lucia Spedo. História da Educação Brasileira: leituras. São Paulo: Pioneira Thomson Learning, 2005.

LONER, Beatriz Ana. Classe operária: mobilização e organização em Pelotas: 18881937. Tese de doutoramento. Tese (Pós-Graduação em Sociologia). UFRGS. Porto Alegre, 1999.

LONER, Beatriz Ana; GILL, Lorena Almeida; MAGALHÃES, Mário Osório (orgs.). Dicionário de História de Pelotas. Pelotas: ed. UFPel, 2010.

LOPES, André Luís Borges. A modernização do espaço urbano em Pelotas e a Companhia Telefônica Melhoramento e Resistência (1947-1957). Dissertação. (Programa de Pós-Graduação em História das Sociedade Ibéricas e Americanas). PUC-RS, 2007, 130p.

OLIVEIRA, Romualdo Portela de. A educação na Assembleia Constituinte de 1946. In: FAVERO, Osmar (org.). A Educação nas constituintes brasileiras (1823-1988). Campinas: Autores Associados, 2005, p. 153- 189.

ORÇADA em um bilhão e 980 milhões a receita do município no próximo ano. Diário Popular. Pelotas, 30 nov. 1963, p. 6.

PESAVENTO, Sandra Jatahy. História do Rio grande do Sul. Porto Alegre: Mercado Aberto, 1985.

PIMENTEL, Fortunato. Aspectos gerais de Pelotas. Porto Alegre: Thipografhia Gundlach, 1940.

PREFEITURA MUNICIPAL DE PELOTAS. Decreto nํ 113. Dispõe sobre o regulamento dos professores especializados. 31 de janeiro de 1947a. 


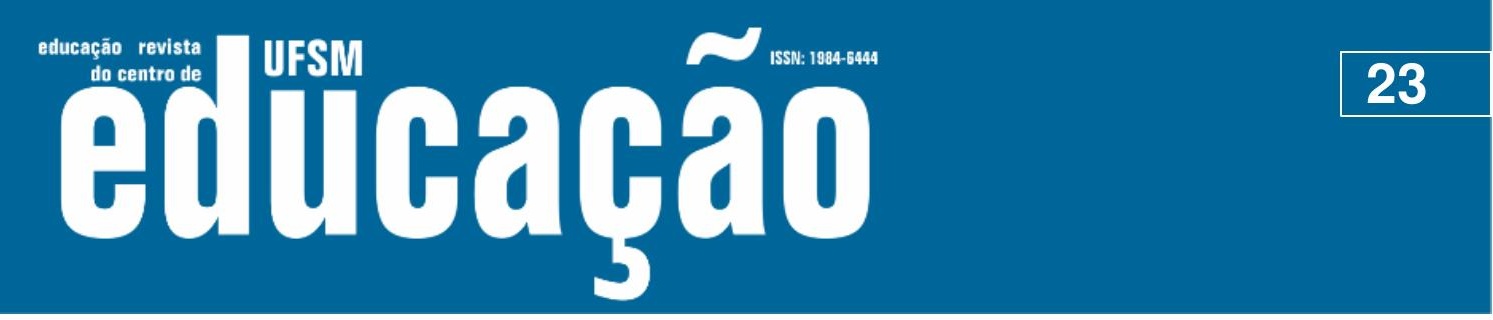

ISSN: 1984-6444 | http://dx.doi.org/10.5902/1984644436332

PREFEITURA MUNICIPAL DE PELOTAS. Decreto nํ 116. Regulamenta o ensino público municipal. 8 de fevereiro de 1947b.

PREFEITURA MUNICIPAL DE PELOTAS. Decreto no 246. Aprova o Regulamento que dá Organização aos Serviços Internos Municipais. 18 de setembro de 1951.

PREFEITURA MUNICIPAL DE PELOTAS. Decreto n 326 . Regulamenta o ensino público municipal. 15 de fevereiro de 1957.

PREFEITURA MUNICIPAL DE PELOTAS. Decreto-Lei no 78. Dispõe sobre o Regimento Interno dos Grupos Escolares e Escolas Isoladas do Município. Aprovado em 4 de novembro de 1944. Pelotas, 1945. (Biblioteca Pública de Pelotas - DPM - 031).

PREFEITURA MUNICIPAL DE PELOTAS. Lei no 112. Autoriza a aquisição de um prédio e respectivo terreno para uma escola. 25 de agosto de 1949.

PREFEITURA MUNICIPAL DE PELOTAS. Lei no 131. Autoriza a receber em doação de um terreno para uma escola. 20 de outubro de 1949.

PREFEITURA MUNICIPAL DE PELOTAS. Portaria Circular no 2. Secretaria de Educação e Saúde Pública. 20 de fevereiro de 1941. Acervo Bibliotheca Publica Pelotense.

PREFEITURA MUNICIPAL DE PELOTAS. Portaria Circular no 12. Diretoria de Educação de Pelotas. 24 de março de 1942. Acervo Bibliotheca Publica Pelotense.

PREFEITURA MUNICIPAL DE PELOTAS. Relatório municipal de 1939, apresentado ao Exm. Sr. Coronel Oswaldo Cordeiro de Farias pelo Exmo. Sr. Albuquerque Barros, 1939. Disponível no Arquivo Histórico do RS.

PREFEITURA MUNICIPAL DE PELOTAS. Relatório municipal de 1947, apresentado ao Exm. Sr. Governador do Estado pelo prefeito Procópio Duval Gomes de Freitas. Pelotas: Gráfica da livraria do Globo. 1947c. Disponível no acervo do Centro de Estudos e Investigações em História da Educação (CEIHE): https://wp.ufpel.edu.br/ceihe/repositorio-pelotas/.

PROJETO de Lei no 212, of. N. 602/50 e 630/50. Câmara orça a receita e fixa a despesa do município para o exercício de 1951. Diário Popular. Pelotas, 14 dez. 1950, p. 2.

PROJETO de Lei no 295, of. N. 822/51. Câmara orça a receita e fixa a despesa do município para o exercício de 1952. Diário Popular. Pelotas, 18 dez. 1951, p. 7, 8 e 9.

RAGAZZINI, Dario. Para quem e o que testemunham as fontes da História da Educação? Educar em Revista. Curitiba: Ed. da UFPR, n.18, jul./ dez., 2001, p. 13 29. 


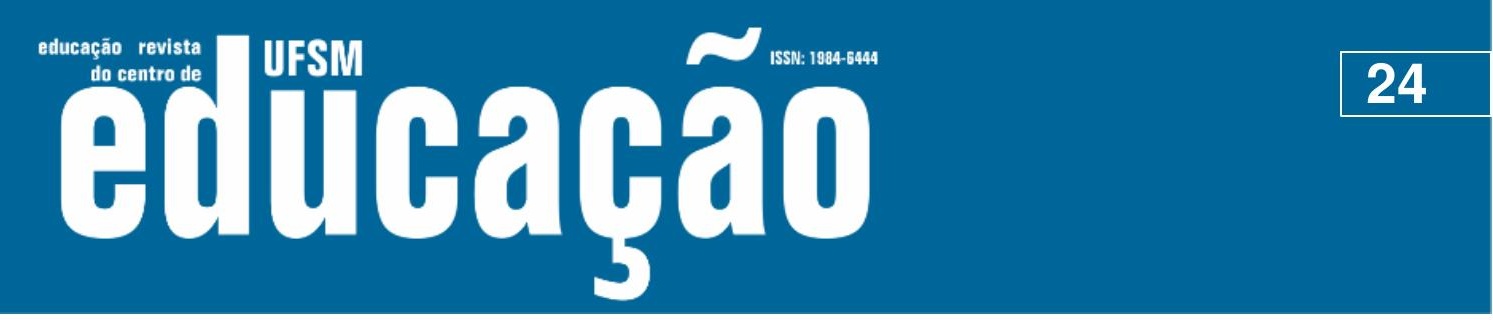

ISSN: 1984-6444 | http://dx.doi.org/10.5902/1984644436332

ROCHA, Marlos Bessa Mendes da. Tradição e modernidade na educação: o processo constituinte de 1933-34. P. 119-138. In: FAVERO, Osmar (org.). A educação nas constituintes brasileiras 1823-1988. Campinas: $3^{a}$ ed. Autores Associados, 2005, p.119-138.

SAVIANI, Demerval. O Legado Educacional do "Longo Século XX" Brasileiro. In: SAVIANI, Demerval (org.). O Legado Educacional do século $\mathbf{X X}$ no Brasil. Campinas: $2^{\text {a }}$ ed., Autores Associados, 2006, p. 9 - 58.

SOUZA, Rosa Fátima de. História da organização do trabalho escolar e do currículo no século XX (ensino primário e secundário no Brasil). São Paulo: Ed. Cortez, 2008.

SOUZA, Rosa Fátima de; ÁVILA, Virgínia Pereira da Silva de. As disputas em torno do ensino primário rural (São Paulo, 1931-1947). Hist. Educ. Online, Porto Alegre, n.43, p. 13-32, v. 18, mai./ago., 2014.

TAMBARA, Elomar Calegaro; QUADROS, Claudemir de; BASTOS, Maria Helena Camara. A educação (1930-80). In: GERTZ, Rene; BOEIRA, Nelson; GOLIN, Tau (orgs). República. Da revolução de 1930 à ditadura militar (1930-1985). Passo Fundo: Méritos, 2007, vol. 4, p. 315 a 333.

VILELA, Cláudia Oliveira Cury; RIBEIRO, Betânia de Oliveira Laterza. Municipalidade e Municipalização da Educação Primária no Brasil. Revista Horizontes, São Paulo: Edusf, v. 29, no 2, jul./dez 2011, p. 71 - 84.

\section{Correspondência}

Magda de Abreu Vicente - Fundação Universidade Federal de Rio Grande - Av. Itália, s/n, Km 8, Carreiros, CEP 96203-900, Rio Grande, Rio Grande do Sul, Brasil.

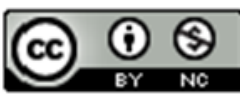

This work is licensed under a Creative Commons Attribution-NonCommercial 4.0 International (CC BY-NC 4.0)

\section{Notas}

\footnotetext{
${ }^{1}$ Segundo Souza; Ávila (2014, p. 9 e 10) “em meados dos anos 1930, por exemplo, 77,04\% da população vivia na zona rural, contra 22,96\% na zona urbana. [...] Na zona rural, 19.763. 782 (72\%) da população adulta não sabia ler nem escrever e o sabiam apenas 7.556,007 (28\%)".

${ }^{2}$ Segundo este autor, o primeiro período seria de 1890 até 1930 que ocorreu "com a implantação dos grupos escolares, e corresponderia a história da escola pública". O último período seria de 1961 a 1996 com a unificação da educação nacional "abrangendo as redes pública e privada sob o influxo direto ou indireto de uma concepção produtivista de escola” (SAVIANI, 2006, p. 20 e 21).
} 


\title{
N

ISSN: 1984-6444 | http://dx.doi.org/10.5902/1984644436332

\begin{abstract}
${ }^{3}$ Após 1959, não constava nas legislações consultadas a abertura ou mudança de nome de escolas municipais.
${ }^{4}$ As leis encontradas relativas ao governo de Joaquim Duval foram as seguintes: Lei n. 31 de 26/7/1948 (Recebe doação da Sociedade Evangélica Escolar Santa Belmira dos moradores da colônia São Manoel); Lei n. 94 de 4/4/1949 (Doação de um terreno de Ercio Barbosa da Costa, situado no antigo $4^{\circ}$ distrito da Capela Velha da Buena, lugar denominado Brisolara); Lei n. 131 de 20/09/1949 (recebe doação de um terreno de 2 ha da firma de Pedro Osório e Cia. Ltda); Lei n. 157 de 15/12/ 1949 (recebe doação de 1ha de Frederico Schiavon, na Estrada Geral, Serro da Vigia ao Passo do Toledo); Lei n. 160 de 15/12/1949 (recebe doação de um terreno de 6 ha da Sociedade Escolar da Colônia Palmeira, no subdistrito de Santa Silvana); Lei n. 272 de 5/09/1951 (recebe doação de 1ha de João Frederico Hirdes, em Campo Grande, distrito do Capão do Leão). Cabe ressaltar ainda que, até 1961, quando analisamos as leis e decretos municipais, outras legislações foram encontradas sobre doações de terrenos para as escolas, todas disponíveis no site da prefeitura de Pelotas.
\end{abstract}

${ }^{5}$ Não tivemos acesso ao discurso realizado pelo candidato do PTB, visto que o jornal Diário Popular era claramente favorável à candidatura do peessedebista e não reproduziu o discurso de Meneghetti. Sobre esse período, não existe outro jornal disponível para consulta na Bibliotheca Pública de Pelotas.

${ }^{6}$ Este censo pode ser consultado em: https://atlassocioeconomico.rs.gov.br/grau-de-urbanizacao Acesso em 05 dez. 2018. 